\title{
Cementos con cenizas volantes
}

\author{
MAURICIO OSSA M.* \\ HECTOR JORQUERA S.**
}

\section{$R E S U M E N$}

Casi la generalidad de los estudios realizados sobre cementos con adición de cenizas volantes se refieren a sus características y comportamiento en pastas, morteros y hormigones, siempre en relación con aquéllos. del cemento portland. Esta vez, se desarrolló un trabajo experimental orientado a relacionar entre sí los cementos con adiciones de cenizas volantes y de puzolana natural. Para ello se fabricaron a escala de laboratorio cementos de ambos tipos, empleando como materias primas comunes clínker y yeso y, como variables, diferentes porcentajes de las dos adiciones, que cumplieron previamente los requisitos normalizados en cuanto a sus actividades puzolánicas. La calidad de los cementos fabricados resultó adecuada y concordante con la del cemento portland-puzolánico obtenido a escala industrial con los mismos clinker, yeso y puzolana natural de este estudio. Posteriormente, se deteminaron las características de los cementos experimentales y se confeccionaron morteros normales para la realización de ensayos fisicos y mecánicos. Los resultados de ensayos indicaron que los cementos con adición de cenizas volantes (CCV) requieren menos agua para consistencia normal, presentan tiempos de fraguado mayores y expansiones en autoclave menores que los cementos con adición de puzolana (CP). Los calores de hidratación a 7 y 28 dias de edad fueron aproximadamente similares para ambos tipos de cemento. En morteros normales, los cementos CCV mostraron menor retracción de secado, mayor retentividad y mayor fluidez (para igual cantidad de agua) que los cementos CP. En los ensayos de exudación se observó que ésta depende más de la finura que el tipo de adición. Finalmente, los ensayos mecánicos señalaron que las resistencias a compresión y flexotracción de los morteros con cementos $C C V$ son menores a edades inferiores que 14 dias (del orden de 5 a $10 \%$ a un día de edad), pero que a partir de entonces pasan a ser mayores que las de los morteros con cementos $C P$, con diferencias crecientes que alcanzan hasta un $15 \%$ en ensayos a compresión, a 120 dias de edad, para adiciones de 20 y $30 \%$.

\section{$S U M M A R Y$}

Almost all the studies carried out on cements with the addition of flying ash refer to their characteristics and behaviours in pastes, mortars and concretes, always in relation with Portland cement. This time, there has been developed an experimental work oriented to relate between themselves the cements with additions of flying ash and of natural puzzolan. For this there were manufactured on laboratory scale cements of both types, using the same raw materials, clinker and plaster, and as variables, different porcentages of the two additions, which previously complied with the standard requisites concerning their puzzolanic (??) activities. The quality of the cements manufactured was adequate and in accord with that of Portland-puzzolanic (??) cement obtained on an industrial scale with the same clinkers, plaster and natural puzzolan (??) of this study. Later there were determined the characteristics of the experimental cements and normal mortars were prepared for carrying out physical and mechanical tests. The test results indicated that the cements with addition of flying ash (CCV) require less water for normal consistency, present greater times of forging and less expansions in autoclave than the cements with the addition of puzzolan (CP). The hydration heats at 7 and 28 days were approximately similar for both types of cement. In normal mortars, the CCV cements showed less retraction of drying, greater retentivenness and greater fluidity (for the same quantity of water) than the CP cements. In the exudation tests it was observed that this depends more on the fineness than the type of addition. Finally, the mechanical tests showed that the resistances to compression and flexotraction of the mortars with $\mathrm{CCV}$ cements are lesser at ages less than 14 days (about 5 to $10 \%$ at one day of age), but from then on become greater than those of mortars with CP cements, with growing differences which reach $15 \%$ in compression tests, at 120 days of age, for additions of 20 and $30 \%$.

* Investigador del IDIEM. Universidad de Chile.

** Ingeniero Civil, Universidad de Chile. 


\section{INT RO D U C C I O N}

Los efectos de las cenizas volantes en el hormigón han sido estudiados en numerosas investigaciones, sea como reemplazo de parte del cemento portland, sea simplemente como adición en el hormigón. En el primer caso, que es mayoritario en estudios, se ha comprobado que cuando se emplean las cenizas volantes en porcentaje de 10 a $30 \%$ de reemplazo, el agua necesaria para mezclado por unidad de volumen del hormigón generalmente no aumenta y a veces puede ser reducida; que la resistencia en las primeras edades, hasta los 28 días disminuye, pero en edades posteriores puede ser igual o mayor que el hormigón normal; que los cambios de volumen no son significativamente afectados; que se reducen el calor de hidratación y la permeabilidad; que aumenta la cantidad de aditivo necesario para una determinada incorporación de aire; y finalmente, que la reducción de la expansión dañina provocada por la reacción álcali-árido es menos reducida que cuando se emplean otras puzolanas. En el segundo caso, cuando las cenizas volantes se emplean como adición en el hormigón, se ha comprobado que, en cantidades de 15 a $30 \%$ en peso de la arena de hormigones pobres, se mejora notablemente la trabajabilidad y se obtienen mayores resistencias a todas las edades. Obviamente las cenizas volantes contribuyen a suplir con eficacia la carencia de finos de un hormigón pobre.

Menos frecuentes son los estudios realizados con cenizas volantes empleadas en la fabricación de cementos, adicionadas durante el proceso de molienda, comparándolos con cementos portland sin adición. Los resultados obtenidos en la generalidad de ellos, señalan ventajas y desventajas semejantes a las mostradas por cementos con adiciones de puzolanas naturales. La razón es comprensible, puesto que las puzolanas naturales y las cenizas volantes provienen de fenómenos relativamente comparables. Pero ¿cuál es la relación de los comportamientos de estos cementos entre si?

Por lo expuesto anteriormente se consideró de interés establecer las reales semejanzas de ambos productos adicionándolos a clínker y yeso mediante molienda conjunta y procediendo a un estudio comparativo de los cementos obtenidos.

Estos cementos experimentales, difieren de aquéllos fabricados a nivel industrial, por causas como: tipo de molino empleado, carga de bolas del molino, diámetro de las bolas, temperaturas alcanzadas por los cementos en el molino y, por último, cantidades producidas. Por ello los resultados de estas experiencias, tienen como objetivo establecer solamente una comparación entre cementos fabricados con adición de cenizas volantes y de puzolana y determinar la influencia del porcentaje de ambas adiciones.

\section{Selección de materiales}

Cenizas volantes. - Las cenizas son los residuos de la combustión de carbón pulverizado en centrales térmicas. Los productos de esta combustión se subdividen en cenizas volantes y de hogar. Los primeros, son residuos volátiles obtenidos a lo largo del trayecto de los gases de la combustión del carbón que son evacuados por la chimenea de la caldera (1). Las propiedades de estas cenizas varian ampliamente según el tipo de carbón, el residuo de cenizas, el grado de pulverización y el tipo de colectores empleados. Aún cuando estas cenizas se obtengan de una misma fuente de producción, sus propiedades físicas y químicas presentan cierto rango de variación. Las cenizas de hogar, por su parte, se obtienen desde el fondo del hogar de la caldera y el tamaño de sus partículas es entonces mayor que el de las cenizas volantes. Su producción corresponde al $20 \%$ (3), aproximadamente, del total de cenizas obtenidas.

Para el presente estudio, se utilizaron cenizas provenientes de una central térmica que tiene una potencia instalada de $330 \mathrm{Mw}$. Dentro de las exigencias que debe cumplir el carbón utilizado figuran un poder calorífico mínimo de $6.000 \mathrm{kcal} / \mathrm{kg}$ y un residuo en cenizas de $17 \%$ como máximo. 
Las características químicas y fisicas de las cenizas volantes empleadas para la adición de los cementos experimentales se indican en Tablas I, II y III.

T ABLA I

Composición química de cenizas volantes

\begin{tabular}{|l|c|}
\hline \multicolumn{1}{|c|}{ Componentes } & Cantidad, \% \\
\hline Sílice $\left(\mathrm{SiO}_{2}\right)$ & 49,10 \\
Oxido de aluminio $\left(\mathrm{Al}_{2} \mathrm{O}_{3}\right)$ & 26,18 \\
Oxido férrico $\left(\mathrm{Fe}_{2} \mathrm{O}_{3}\right)$ & 14,63 \\
Oxido de magnesio $(\mathrm{MgO})$ & 1,13 \\
Oxido de calcio $(\mathrm{CaO})$ & 5,84 \\
Trióxido de azufre $\left(\mathrm{SO}_{3}\right)$ & 0,58 \\
Oxido de sodio $\left(\mathrm{Na}_{2} \mathrm{O}\right)$ & 1,52 \\
Cloruros $\left(\mathrm{Cl}^{-}\right)$ & Trazas \\
Oxido de potasio $\left(\mathrm{K}_{2} \mathrm{O}\right)$ & 0,77 \\
Pérdida por calcinación & 1,27 \\
Residuo insoluble & 77,31 \\
\hline
\end{tabular}

T ABLA II

Propiedades fisicas de cenizas volantes

\begin{tabular}{|l|l|}
\hline \multicolumn{1}{|c|}{ Propiedades } & Valor \\
\hline Peso especifico & 2,212 \\
Superficie especifica $\left(\mathrm{cm}^{2} / \mathrm{g}\right)$ & 2,100 \\
Densidad aparente $\left(\mathrm{kg} / \mathrm{dm}^{3}\right)$, suelta & 0,97 \\
\hline
\end{tabular}

T ABLA III

Granulometría de cenizas volantes

\begin{tabular}{|c|c|}
\hline Tamiz ASTM N. $^{{ }^{\circ}}$ & \% retenido parcial \\
\hline 10 & 0,0 \\
12 & 0,0 \\
18 & 0,0 \\
35 & 0,3 \\
100 & 1,8 \\
200 & 8,6 \\
$325^{*}$ & 28,5 \\
Residuo & 60,8 \\
\hline
\end{tabular}

* Tamizado húmedo.

Puzolana. - En la zona de Santiago, existen grandes yacimientos de puzolana, de tipo riolítico, provenientes de morrenas de pómez que tuvieron su origen durante la época glacial, por las erupciones de los volcanes de la cuenca Tupungato, en San José de Maipo, y que siguieron el curso del valle por los cauces antiguos de los ríos Maipo y Mapocho. Uno de esos yacimientos se encuentra en la localidad de Pudahuel y corresponde al lugar de origen de la puzo-

T A B LA IV

Composición química de la puzolana natural

\begin{tabular}{|l|c|}
\hline \multicolumn{1}{|c|}{ Componentes } & Cantidad, \% \\
\hline Silice $\left(\mathrm{SiO}_{2}\right)$ & 71,22 \\
Oxido de aluminio $\left(\mathrm{Al}_{2} \mathrm{O}_{3}\right)$ & 15,77 \\
Oxido férrico $\left(\mathrm{Fe}_{2} \mathrm{O}_{3}\right)$ & 1,59 \\
Oxido de magnesio $(\mathrm{MgO})$ & 1,92 \\
Oxido de calcio $(\mathrm{CaO})$ & 1,21 \\
Trioxido de azufre $\left(\mathrm{SO}_{3}\right)$ & 0,13 \\
Oxido de sodio $\left(\mathrm{Na}_{2} \mathrm{O}\right)$ & 0,44 \\
Oxido de potasio $\left(\mathrm{K}_{2} \mathrm{O}\right)$ & 3,49 \\
Cloruros $\left(\mathrm{Cl}^{-}\right)$ & Trazas \\
Pérdida por calcinación $\left(950^{\circ} \mathrm{C}\right)$ & 4,57 \\
Residuo insoluble & 86,53 \\
\hline
\end{tabular}
lana utilizada para la fabricación de los cementos experimentales. Su composición quimica y sus propiedades físicas aparecen en Tablas IV y V.

TABLA V

Propiedades fisicas de la puzolana*

\begin{tabular}{|l|c|}
\hline \multicolumn{1}{|c|}{ Propiedades } & Valor \\
\hline Peso especifico & 2,359 \\
Superficie especifica $\left(\mathrm{cm}^{2} / \mathrm{g}\right)$ & 300 \\
Densidad aparente $\left(\mathrm{kg} / \mathrm{dm}^{3}\right)$, suelta & 0,98 \\
\hline
\end{tabular}

* Puzolana bajo tamiz ASTM N. ${ }^{\circ} 35$.

Clínker.-El clínker utilizado se obtuvo industrialmente por via seca. Su peso especifico fue de 3,153 y presentó la composición química que se indica en Tabla VI. 
T A B LA VI

Composición química del clínker

\begin{tabular}{|l|c|}
\hline \multicolumn{1}{|c|}{ Componentes } & Cantidad, \% \\
\hline Silice $\left(\mathrm{SiO}_{2}\right)$ & 20,00 \\
Oxido férrico $\left(\mathrm{Fe}_{2} \mathrm{O}_{3}\right)$ & 2,95 \\
Oxido de aluminio $\left(\mathrm{Al}_{2} \mathrm{O}_{3}\right)$ & 6,95 \\
Oxido de magnesio $(\mathrm{MgO})$ & 1,59 \\
Oxido de calcio $(\mathrm{CaO})$ total & 64,80 \\
Trioxido de azufre $\left(\mathrm{SO}_{3}\right)$ & 1,85 \\
Oxido de sodio $\left(\mathrm{Na}_{2} \mathrm{O}\right)$ total & 0,58 \\
Oxido de potasio $\left(\mathrm{K}_{2} \mathrm{O}\right)$ total & 0,91 \\
Pérdida por calcinación & 0,32 \\
Residuo insoluble & 0,29 \\
Oxido de calcio $(\mathrm{CaO})$ libre & 1.00 \\
\hline
\end{tabular}

Según R.H. Bogue, la composición de fases de este clínker se presenta como aparece en Tabla VII.

Yeso.-Se empleó un yeso proveniente de la zona norte del pais, a $300 \mathrm{~km}$ de Santiago, que presentó un peso específico de 2,525 y la composición quimica que se señala en Tabla VIII.
TABLA VII

Composición potencial de fases del clínker

\begin{tabular}{|l|c|}
\hline \multicolumn{1}{|c|}{ Fase } & Cantidad, \% \\
\hline Silicato tricálcico $\left(\mathrm{C}_{3} \mathrm{~S}\right)$ & 52 \\
Silicato dicálcico $\left(\mathrm{C}_{2} \mathrm{~S}\right)$ & 18 \\
Aluminato tricálcico $\left(\mathrm{C}_{3} \mathrm{~A}\right)$ & 13 \\
Ferroaluminato tetracálcico $\left(\mathrm{C}_{4} \mathrm{AF}\right)$ & 9 \\
\hline
\end{tabular}

TABLA VIII

Composición química del yeso

\begin{tabular}{|l|c|}
\hline \multicolumn{1}{|c|}{ Componentes } & Cantidad, \% \\
\hline Silice y materias insolubles & 16.56 \\
Oxidos de hierro y de aluminio $\left(\mathrm{R}_{2} \mathrm{O}_{3}\right)$ & 2,26 \\
Oxido de calcio $(\mathrm{CaO})$ & 28,88 \\
Oxido de magnesio $(\mathrm{MgO})$ & 0,72 \\
Trióxido de azufre $\left(\mathrm{SO}_{3}\right)$ & 32,10 \\
Anhidrido carbónico $\left(\mathrm{CO}_{2}\right)$ & 5.68 \\
Cloruro de sodio $(\mathrm{NaCl})$ & 0.17 \\
Agua libre $\left(\mathrm{H}_{2} \mathrm{O}\right)$ & 0,50 \\
Agua combinada $\left(\mathrm{H}_{2} \mathrm{O}\right)\left(220^{\circ} \mathrm{C}\right)$ & 4.80 \\
Pérdida por calcinación $\left(950^{\circ} \mathrm{C}\right)$ & 19.14 \\
\hline
\end{tabular}

\section{Actividad puzolánica de las adiciones}

Las calidades de las adiciones para la fabricación de cementos se controlaron mediante la actividad desarrollada en morteros de cal-adición arena. Se obtuvieron asi los resultados señalados en Tabla IX.

TABLA IX

Actividad puzolánica de las adiciones (1)

\begin{tabular}{|c|c|c|}
\hline Tipo de adición & $\begin{array}{c}\text { Consistencia normal pasta } \\
\text { adición-cal. Agua, ml }\end{array}$ & $\begin{array}{c}\text { Resistencia a compresión a 7 ds. } \\
\text { Mortero de cal-adición-arena kg/m } \mathbf{c m}^{2} \text { (2) }\end{array}$ \\
\hline Puzolana & 176 & 76.7 \\
Cenizas volantes & 190 & 64.7 \\
\hline
\end{tabular}

(1) Según norma INN NCh 161. E Of 68.

(2) Promedio de 9 valores obtenidos por mezcla. La norma de ensayo exige una resistencia a compresion minima a los 7 dias de edad, igual o superior a $42 \mathrm{~kg} / \mathrm{cm}^{2}$.

\section{Equipos de molienda}

La molienda de los cementos experimentales se efectuó utilizando una chancadora de mandíbulas con un motor de $5 \mathrm{HP}$ y un molino cónico de bolas con sistema completo de clasificación de aire, recolector de productos pulverizados y ventilador de evacuación. Los pesos y diámetros de la carga de bolas del molino fue: $90 \mathrm{~kg}$ de 1", $45 \mathrm{~kg}$ de 1 1/2" y $45 \mathrm{~kg}$ de 2 ". Ambos equipos aparecen en las figuras 1 y 2 . 


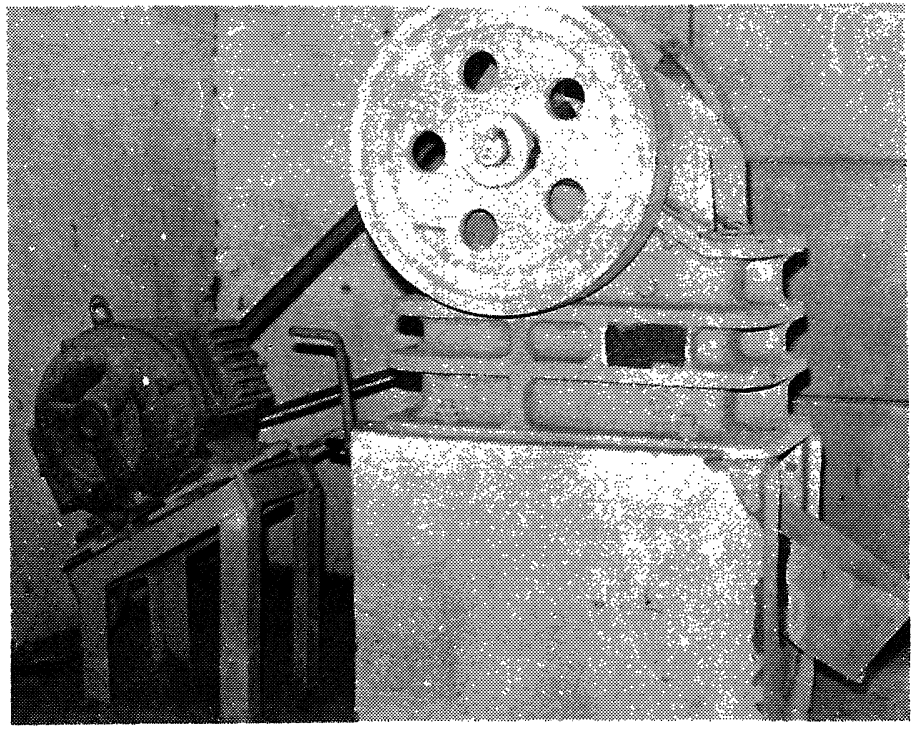

Fig. 1.-Chancadora de mandibulas marca Denver.

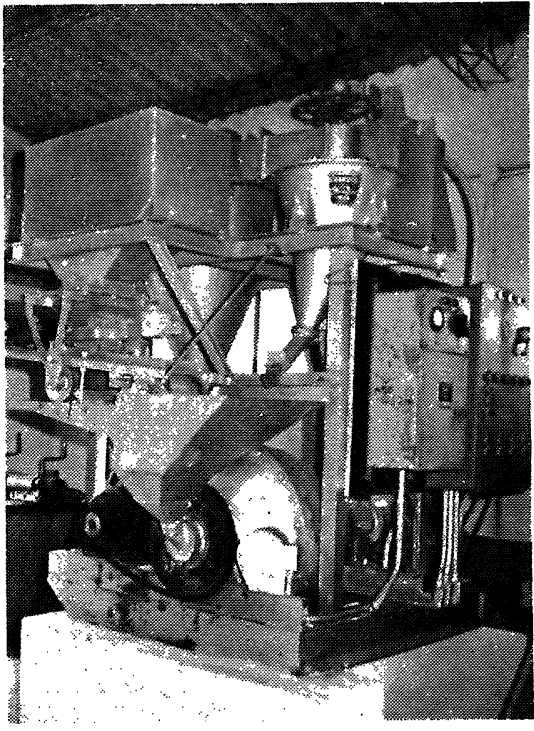

Fig. 2.-Molino conico de bolas con sistema completo de clasificación de aire.

\section{Preparación de materias primas}

Las cenizas volantes se homogeneizaron con el fin de minimizar la dispersión de sus características y propiedades. Similar precaución se tomó con la puzolana natural.

El yeso en estado de piedra de yeso natural y el clínker en estado de esferas de 3 a $20 \mathrm{~mm}$ de diámetro, fueron triturados en la chancadora a fin de mejorar el rendimiento del molino. Luego se procedió a efectuar una molienda por separado de ambos materiales hasta obtener una finura semejante a la de las adiciones, a objeto de tener un cemento homogéneo durante la molienda conjunta. Las finuras alcanzadas en esa molienda previa fueron de 1.750 y $2.850 \mathrm{~cm}^{2} / \mathrm{g}$ para el clínker y el yeso, respectivamente.

\section{Dosificación de los cementos}

Las materias primas se dosificaron en peso. En la tabla $\mathrm{X}$ se muestran las composiciones porcentuales de los cementos experimentales.

TABLA $\mathrm{X}$

Composición de cementos con adiciones

\begin{tabular}{|c|c|c|c|c|}
\hline \multirow{2}{*}{$\begin{array}{c}\text { Tipo } \\
\text { de } \\
\text { cemento }\end{array}$} & Puzolana & Cenizas volantes & Yeso & Clinker \\
\cline { 2 - 5 } & 20 & $/$ & 5 & 75 \\
P-20 & 30 & $/$ & 5 & 65 \\
P-30 & 40 & $/$ & 5 & 55 \\
P-40 & 50 & $/$ & 5 & 45 \\
P-50 & $/$ & 20 & 5 & 75 \\
C-20 & $/$ & 30 & 5 & 65 \\
C-30 & $/$ & 40 & 5 & 55 \\
C-40 & $/$ & 50 & 5 & 45 \\
C-50 & & & & \\
\hline
\end{tabular}




\section{Molienda de los cementos}

Luego de efectuar la trituración y la molienda previa del clínker y del yeso, se procedió a realizar la molienda definitiva de los cementos experimentales introduciendo en el molino clínker, yeso y la adición respectiva en forma simultánea. Primero se cargó el molino con $30 \mathrm{~kg}$ de estos materiales y luego se introdujeron en forma paulatina cargas sucesivas según la cantidad de cemento que fuera saliendo del molino. La finura que se trató de alcanzar en cada cemento experimental fue de $4.000 \mathrm{~cm}^{2} / \mathrm{g}$, aproximadamente, similar a los cementos puzolánicos comerciales.

Lógicamente los tiempos de molienda necesarios para ambos tipos de cementos disminuyeron a medida que aumentaba el porcentaje de adición. También se pudo comprobar que los pesos específicos, obtenidos en forma teórica y experimental para cada tipo de cemento, resultaron similares. Estos hechos permitieron apreciar que la calidad de los procesos de dosificación y molienda resultaron bastante aceptables.

\section{Envasado de los cementos}

Los cementos experimentales se envasaron en bolsas de polietileno con capacidad aproximada de $10 \mathrm{~kg}$ de cemento $\mathrm{c} / \mathrm{u}$. Luego se procedió a colocar esas bolsas en tambores metálicos, provistos de un cierre hermético, que se almacenaron en un ambiente con temperatura entre 18 y $27^{\circ} \mathrm{C}$ y humedad relativa entre 50 y $75 \%$.

\section{Características de los cementos obtenidos}

Para controlar los procesos de cocción y de molienda en la fabricación de cementos, generalmente se les determinan ciertas características quimicas y físicas, algunas de las cuales están limitadas por normas. La Tabla XI muestra los resultados obtenidos por los cementos experimentales en las determinaciones efectuadas.

La norma INN NCh 148. Of 68. "Cemento, terminología, clasificación y especificaciones generales" exige para los cementos portland puzolánicos (menos de $30 \%$ de adición) máximos de $30,0 \%$ de residuo insoluble, $4,0 \%$ de $\mathrm{SO}_{3}$ y 4,0\% de pérdida por calcinación y, para los cementos puzolánicos (adición de puzolana comprendida entre 30 y $50 \%$ ), máximos de 50,0\%, $4,0 \%$ y $5,0 \%$, respectivamente.

T A B LA XI

Características de los cementos

\begin{tabular}{|c|c|c|c|c|c|}
\hline $\begin{array}{c}\text { Cemento } \\
\text { tipo }\end{array}$ & $\begin{array}{c}\text { Residuo } \\
\text { insoluble \% }\end{array}$ & $\begin{array}{c}\text { Contenido de SO } \\
\text { \% (teórico) }\end{array}$ & $\begin{array}{c}\text { Pérdida por } \\
\text { calcinación \% }\end{array}$ & $\begin{array}{c}\text { Peso } \\
\text { especifico }\end{array}$ & $\begin{array}{c}\text { Superficie } \\
\text { especifica } \mathbf{~ c m}^{2} / \mathbf{g}\end{array}$ \\
\hline P-20 & 16,9 & 3.1 & 2.6 & 2.936 & 4.150 \\
P-30 & 27,1 & 2.9 & 2.8 & 2.819 & 3.750 \\
P-40 & 34,9 & 2.7 & 3.1 & 2.783 & 4.100 \\
P-50 & 42,0 & 3.5 & 3.9 & 2.700 & 4.900 \\
C-20 & 17,0 & 3.0 & 2.5 & 2.949 & 4.200 \\
C-30 & 23.9 & 2.9 & 2.0 & 2.870 & 3.600 \\
C-40 & 30.7 & 2.8 & 2.1 & 2.796 & 3.875 \\
C-50 & 40.7 & NCh 147. Of 69. & NCh 154. Of 69. & NCh 159. Of 70. \\
\hline
\end{tabular}

* Se sumaron ponderadamente los contenides de $\mathrm{SO}_{3}$ de los materiales dosifícados. 
Los residuos insolubles y las pérdidas por calcinación resultantes en estos cementos experimentales guardan estrecha relación con las caracteristicas propias de las adiciones empleadas (ver Tablas I y IV).

Las superficies específicas obtenidas, lamentablemente, no resultaron similares en todos los tipos de cemento, especialmente el designado como P-50 que mostró una finura excesiva.

\section{Comportamiento de cementos experimentales}

Para establecer la comparación entre los cementos con adiciones de puzolanas naturales y de

T ABLA XII

Ensayos fisicos corrientes

\begin{tabular}{|c|c|c|c|c|c|c|}
\hline \multirow{2}{*}{$\begin{array}{c}\text { Ensayo } \\
\text { Cemento }\end{array}$} & \multirow{2}{*}{$\begin{array}{c}\begin{array}{c}\text { Consistencia } \\
\text { normal }\end{array} \\
\text { Agua \% }\end{array}$} & \multicolumn{2}{|c|}{ Tiempos de fraguado } & \multirow{2}{*}{$\begin{array}{c}\begin{array}{c}\text { Expansión } \\
\text { en autoclave }\end{array} \\
\text { Expansión \% }\end{array}$} & \multicolumn{2}{|c|}{ Calor de hidratación } \\
\hline & & Inicio \% & Fin \% & & Edad, 7 dias & Edad, 28 dias \\
\hline P-20* & $100 *$ & $100^{*}$ & 130 & $100 *$ & 92 & $100^{*}$ \\
\hline P-30 & 101 & 113 & 147 & 133 & 89 & 96 \\
\hline P-40 & 103 & 110 & 150 & 83 & 73 & 81 \\
\hline P-50 & 111 & 123 & 167 & 17 & 68 & 79 \\
\hline $\mathrm{C}-20$ & 95 & 127 & 163 & 83 & 89 & 100 \\
\hline $\mathrm{C}-30$ & 97 & 137 & 173 & 67 & 92 & 100 \\
\hline C-40 & 95 & 137 & 174 & 21 & 72 & 77 \\
\hline C-50 & 98 & 150 & 193 & 8 & 67 & 72 \\
\hline $\begin{array}{c}\text { Norma de } \\
\text { ensayo }\end{array}$ & $\begin{array}{l}\text { INN NCh } \\
\text { 151. Of } 68 .\end{array}$ & \multicolumn{2}{|c|}{ INN NCh 152. Of 70.} & $\begin{array}{l}\text { INN NCh } \\
157 \text {. Of } 67 .\end{array}$ & \multicolumn{2}{|c|}{ ASTM C $186-78$} \\
\hline
\end{tabular}

* Valores de referencia.

T A B LA XIII

Ensayos fisicos especiales

\begin{tabular}{|c|c|c|c|c|c|c|c|c|c|c|}
\hline \multirow{2}{*}{$\begin{array}{c}\text { Ensayo } \\
\text { Cemento }\end{array}$} & \multicolumn{3}{|c|}{ Contracción por secado } & \multicolumn{3}{|c|}{ Retentividad } & \multicolumn{4}{|c|}{ Exudación** } \\
\hline & $\begin{array}{c}\text { Agua } \\
\text { ml }\end{array}$ & $\begin{array}{c}\text { Fluidez } \\
\%\end{array}$ & $\begin{array}{c}\text { Contrac- } \\
\text { ción } \\
\%\end{array}$ & $\begin{array}{c}\text { Agua } \\
\text { ml }\end{array}$ & $\begin{array}{c}\text { Fluidez } \\
\%\end{array}$ & $\begin{array}{c}\text { Retenti- } \\
\text { vidad } \\
\%\end{array}$ & $\begin{array}{c}\text { Agua } \\
\mathbf{g}\end{array}$ & $\begin{array}{c}\text { Fluidez } \\
\%\end{array}$ & $\begin{array}{c}\mathbf{R}_{\mathbf{B}} \\
\%\end{array}$ & $\begin{array}{l}\mathrm{C}_{\mathrm{B}} \\
\%\end{array}$ \\
\hline $\mathrm{P}-20 *$ & 270 & 110 & $100 *$ & 178 & 112 & $100 *$ & 530 & 109,5 & $100^{*}$ & $100 *$ \\
\hline P-30 & 268 & 112 & 104 & 276 & 112 & 97 & 526 & 107,8 & 116 & 100 \\
\hline P-40 & 272 & 111 & 97 & 276 & 111 & 89 & 540 & 109,2 & 88 & 86 \\
\hline P-50 & 280 & 115 & 113 & 286 & 107 & 82 & 559 & 105,9 & 55 & 56 \\
\hline $\mathrm{C}-20$ & 270 & 108 & 99 & 170 & 110 & 103 & 530 & 105,9 & 51 & 63 \\
\hline C-30 & 268 & 111 & 80 & 262 & 107 & 103 & 526 & 105,6 & 107 & 129 \\
\hline C- 40 & 268 & 111 & 84 & 264 & 113 & 93 & 539 & 108,7 & 103 & 105 \\
\hline C-50 & 262 & 110 & 73 & 264 & 111 & 76 & 517 & 108,3 & 183 & 180 \\
\hline $\begin{array}{c}\text { Norma de } \\
\text { ensayo }\end{array}$ & \multicolumn{3}{|c|}{ ASTM C $157-75$} & \multicolumn{3}{|c|}{ ASTM C 91-71 } & \multicolumn{4}{|c|}{ ASTM C 243-65 } \\
\hline
\end{tabular}

* Valores de referencia.

** $R_{\mathrm{B}}=V_{\mathrm{l}} / A \times t\left(\mathrm{~cm}^{3} / \mathrm{cm}^{2} \cdot s\right)$. $C_{\mathrm{B}}=V_{2} / V_{3}$.
$V_{1}=$ Volumen de agua, medido durante el tiempo $t$.

$V_{2}=$ Volumen de agua, total de agua exudada.

$V_{3}=$ Volumen del cilindro de mortero.

$A=$ Area cubierta por el aro colector.

$t=$ Tiempo durante el cual la exudación ocurre a una razón uniforme 
cenizas volantes, se realizó con ellos una serie de ensayos normalizados por el Instituto Nacional de Normalización, de Chile y por la American Society for Testing and Materials, de Estados Unidos. En general, todos los tipos de cementos fabricados cumplieron los requisitos exigidos para sus clases y grados y aquellos de composición similar a los cementos comerciales existentes tuvieron, a su vez, resultados semejantes.

La expresión de resultados en valores absolutos dificulta a veces un objetivo de comparación. Para obviar esas posibles dificultades se optó por entregar los resultados en valores relativos tomando como base de referencia los resultados obtenidos con el cemento tipo P-20, correspondiente a la clase de los cementos portland-puzolánicos, según norma INN NCh 148.Of68.

Las Tablas XII y XIII muestran los resultados de los ensayos de tipo fisico y las Tablas XIV y $\mathrm{XV}$, los de tipo mecánico-resistente.

TABLA XIV

Ensayos de morteros, a flexotracción (3)

\begin{tabular}{|c|c|c|c|c|c|c|c|c|c|c|}
\hline $\begin{array}{c}\text { Tipo } \\
\text { de } \\
\text { Cemento }\end{array}$ & \multicolumn{10}{|c|}{ Resistencias, \% } \\
\cline { 2 - 10 } & $\mathbf{1 ~ d}$ & $\mathbf{3 ~ d}$ & $\mathbf{7 ~ d}$ & $\mathbf{2 8 ~ d}$ & $\mathbf{6 0 ~ d}$ & $\mathbf{9 0 ~ d}$ & $\mathbf{1 2 0} \mathbf{d}$ & $\mathbf{1}$ año & $\mathbf{2}$ años & $\mathbf{3}$ años \\
\hline P-20 & 64 & 74 & 85 & $100^{*}$ & 122 & 124 & 122 & 122 & 135 & 132 \\
P-30 & 51 & 68 & 76 & 94 & 103 & 115 & 115 & 118 & 129 & 122 \\
P-40 & 43 & 58 & 68 & 82 & - & - & - & - & - & - \\
P-50 & 36 & 50 & 58 & 81 & - & - & - & - & - & - \\
C-20 & 53 & 74 & 85 & 100 & 119 & 122 & 131 & 126 & 129 & 132 \\
C-30 & 43 & 62 & 75 & 97 & 124 & 122 & 129 & 129 & 136 & 132 \\
C-40 & 36 & 60 & 71 & 96 & - & - & - & - & - & - \\
C-50 & 22 & 39 & 53 & 81 & - & - & - & - & - & - \\
\hline
\end{tabular}

* Valor de referencia.

(3) Según Norma INN NCh 158. Of 67.

T ABLA XV

Ensayos de morteros, a compresión (4)

\begin{tabular}{|c|c|c|c|c|c|c|c|c|c|c|}
\hline $\begin{array}{c}\text { Tipo } \\
\text { de } \\
\text { Cemento }\end{array}$ & \multicolumn{10}{|c|}{ Resistencias, \% } \\
\cline { 2 - 10 } & $\mathbf{1 ~ d}$ & $\mathbf{3 ~ d}$ & $\mathbf{7 ~ d}$ & $\mathbf{2 8 ~ d}$ & $\mathbf{6 0 ~ d}$ & $\mathbf{9 0 ~ d}$ & $\mathbf{1 2 0 ~ d}$ & $\mathbf{1}$ año & $\mathbf{2}$ años & $\mathbf{3}$ años \\
\hline P-20 & 55 & 74 & 84 & $100^{*}$ & 114 & 119 & 128 & 140 & 136 & 150 \\
P-30 & 36 & 57 & 72 & 86 & 98 & 106 & 114 & 130 & 131 & 137 \\
P-40 & 29 & 47 & 58 & 78 & - & - & - & - & - & - \\
P-50 & 25 & 38 & 51 & 69 & - & - & - & - & - & - \\
C-20 & 36 & 66 & 82 & 106 & 124 & 134 & 139 & 145 & 141 & 143 \\
C-30 & 30 & 52 & 65 & 91 & 111 & 121 & 127 & 139 & 133 & 136 \\
C-40 & 23 & 47 & 60 & 90 & - & - & - & - & - & - \\
C-50 & 13 & 30 & 40 & 69 & - & - & - & - & - & - \\
\hline
\end{tabular}

* Valor de referencia.

(4) Segün Norma INN NCh 158. Of 67. 


\section{Consistencia normal}

La cantidad de agua necesaria para obtener la consistencia normal es menor en los cementos con cenizas volantes que en los con puzolana, como se aprecia en la figura 3. La forma esférica y la granulometría de las cenizas permiten un mejor acomodamiento de la pasta agua-cemento y una mayor facilidad para que la sonda penetre en la pasta. Al moler el clínker, yeso y ceniza para fabricar los cementos, parte de esta última quedaron sin fracturar, por lo que se cumpliria que estos cementos necesitan menos agua.

El cemento P-50 fue el que necesitó mayor cantidad de agua para alcanzar su consistencia, debido a su mayor finura $\left(4.900 \mathrm{~cm}^{2} / \mathrm{g}\right)$.

\section{Tiempos de fraguado}

Los cementos con cenizas presentan tiempos de fraguado mayores que los con puzolana. Se observa que los tiempos aumentan con el porcentaje de adición (figura 4) y que el intervalo de tiempo transcurrido entre inicio y fin de fraguado son similares en ambos tipos de cementos. La

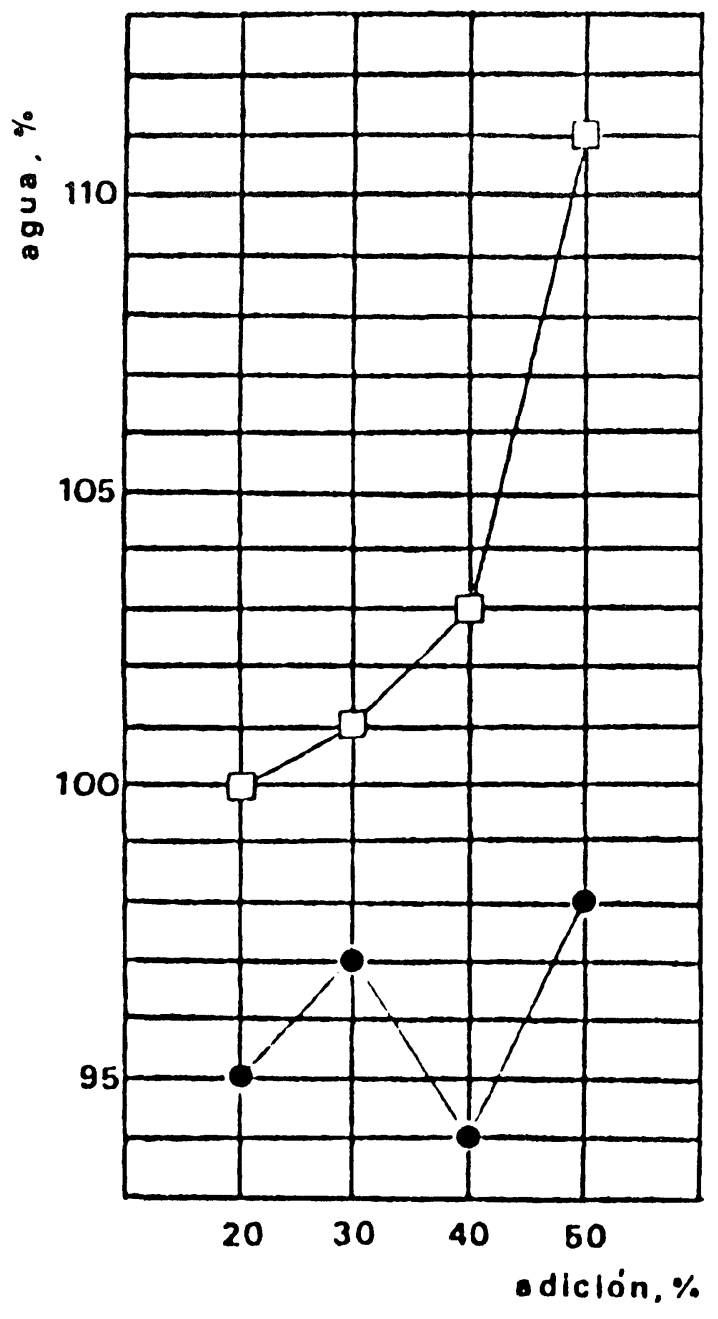

Fig. 3.-Ensayos de consistencia normal.

$\square$ : Cementos con puzolana natural.

-: Cementos con cenizas volantes.

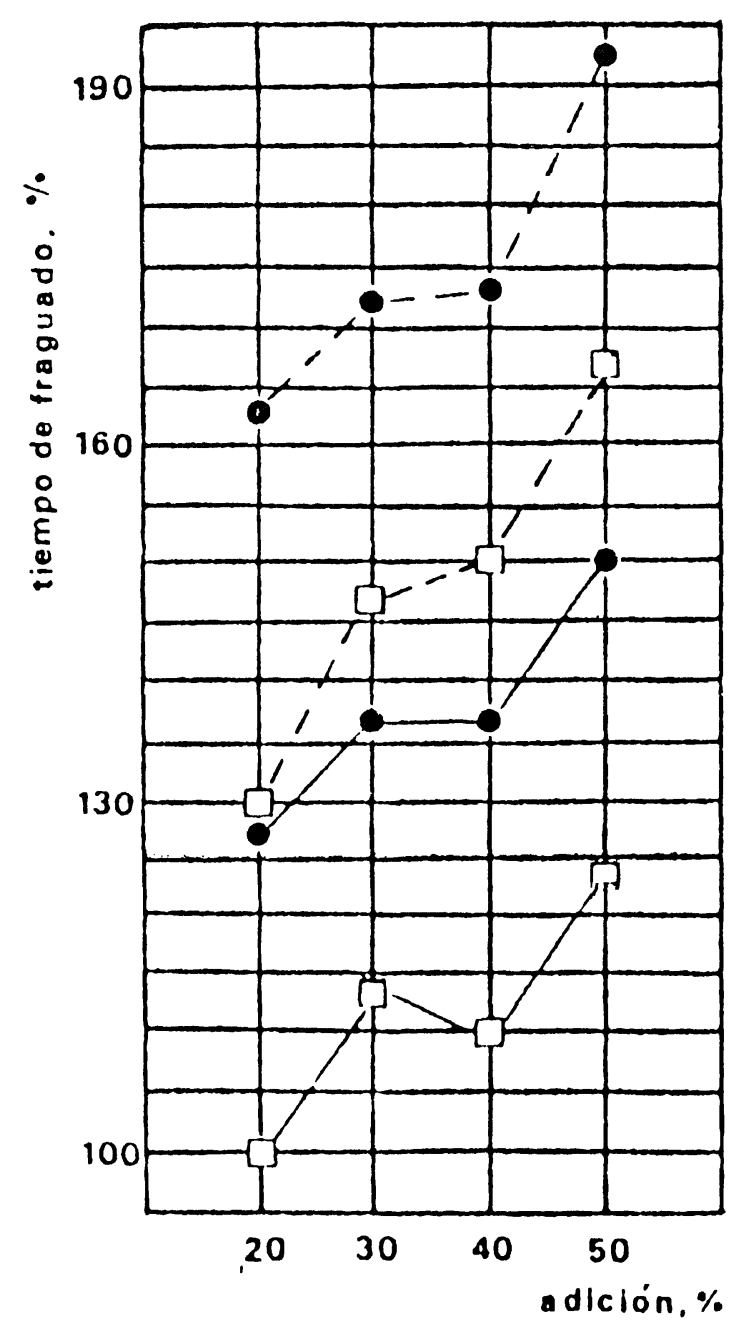

Fig. 4.-Tiempos de fraguado de los cementos.

$\square$ : Cementos con puzolana natural.

-: Cementos con cenizas volantes.

-: Inicio de fraguado.

- - -: Fin de fraguado. 
acción de la película alumino-silícea que rodea cada partícula de ceniza retarda, al parecer, la hidratación de la sílice, por lo que después de cierto tiempo, la ceniza se haría más activa al rodearse de agua y romper la membrana, no alargando el intervalo entre inicio y fin del fraguado.

\section{Expansión en autoclave}

Todos los cementos ensayados presentaron expansiones nulas o pequeñas, muy por debajo del $1,0 \%$ establecido por las normas como límite máximo, lo que era de esperar, por los bajos contenidos de $\mathrm{CaO}$ y $\mathrm{MgO}$ libres en el clínker. Las expansiones de los cementos con cenizas sufren una menor variación que los con puzolana, como se puede observar en el gráfico de la figura 5. Las escorias y a veces las puzolanas presentan valores más elevados en las determinaciones analiticas del $\mathrm{MgO}$ que el clínker, pero su estado físico y mineralógico es distinto, lo que no produce problemas de tipo expansivo. Nurse y otros (4) informan que la adición de cenizas volantes con contenidos de $57,4 \%$ de $\mathrm{SiO}_{2}, 22,2 \%$ de $\mathrm{Al}_{2} \mathrm{O}_{3}$ y $3,4 \%$ de $\mathrm{CaO}$, estabilizan a los cementos con 8 a $15 \%$ de $\mathrm{MgO}$, lo que posiblemente ayude a que los cementos con cenizas tengan menor expansión que aquellos con puzolana.

\section{Calor de hidratación}

Ambos tipos de cementos entregan casi totalmente el calor en las primeras edades, a causa de que el clínker empleado en su fabricación tiene un alto porcentaje de $\mathrm{C}_{3} \mathrm{~S}$ y $\mathrm{C}_{3} \mathrm{~A}$ propio de los llamados "cementos calientes". Mirando la figura 6 y conociendo las finuras de los cementos, se

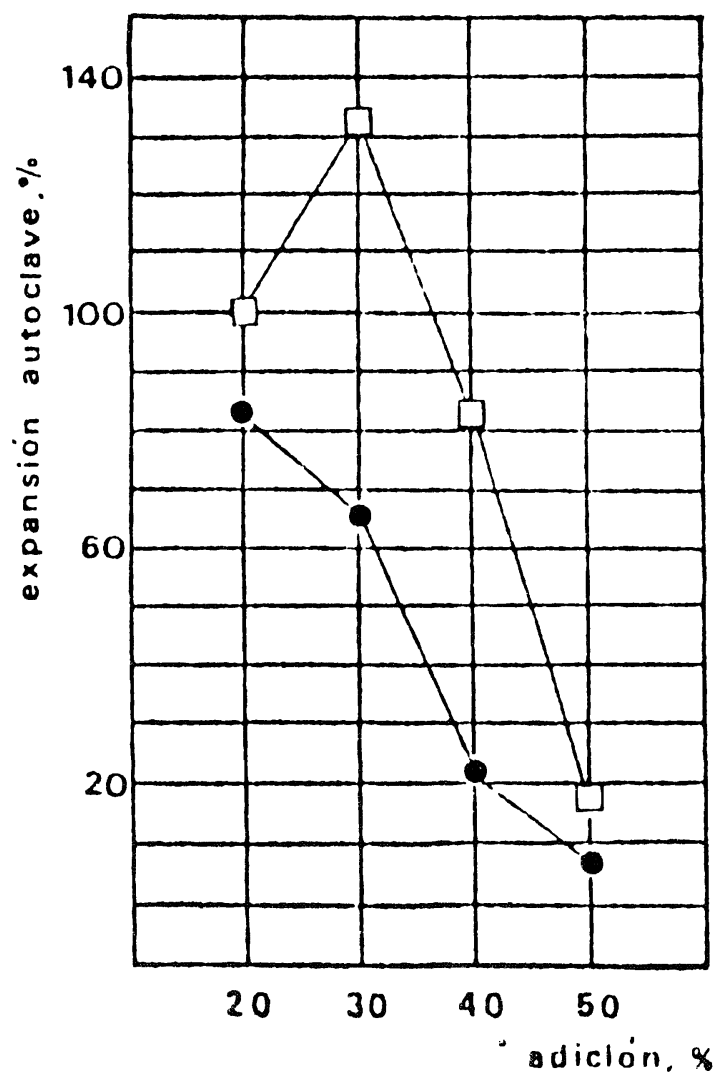

Fig. 5.-Resultados de la expansión en autoclave.

$\square$ : Cementos con puzolana natual.

: Cementos con cenizas volantes.

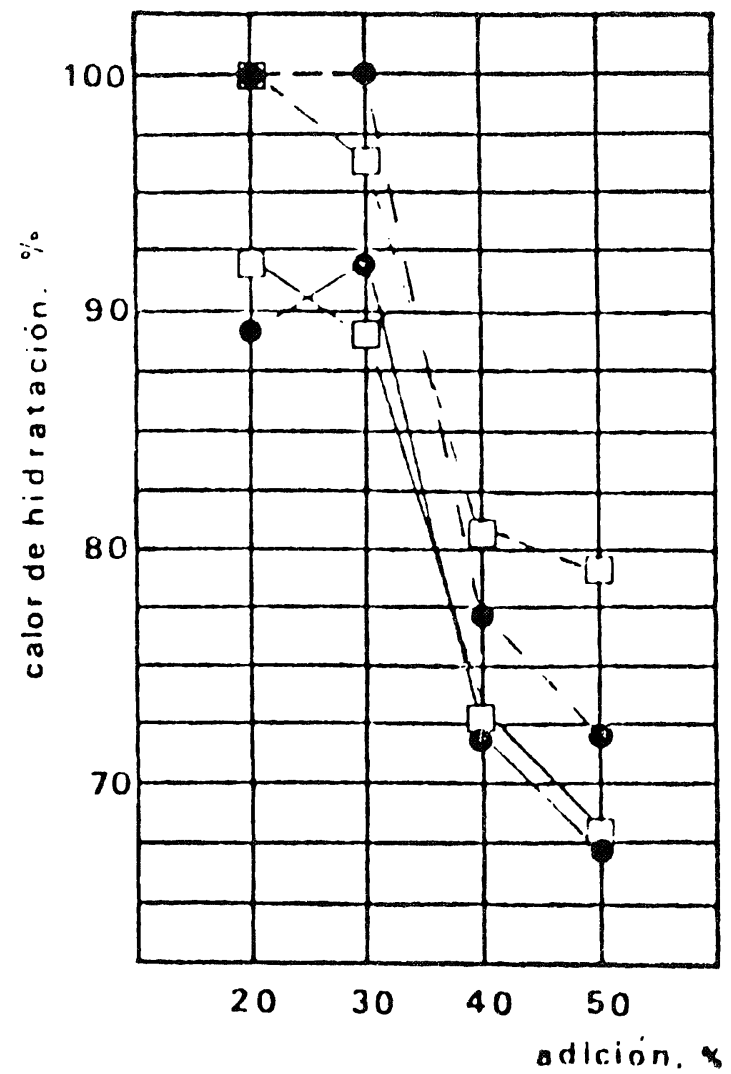

Fig. 6.-Calor de hidratación de los cementos.

-: Calor de hidratación a 7 dias.

- --: Calor de hidratación a 28 dias.

$\square$ : Cementos con puzolana natural.

- Cementos con cenizas volantes. 
observa que a igualdad de porcentaje de adición sólo aquellos con un $50 \%$ presentan grandes diferencias. Estos cementos liberan un calor similar a 7 días de edad, pero a 28 días, P-50 liberan más calor que $\mathrm{C}-50$, posiblemente debido a la diferencia de finuras.

\section{Exudación}

El grado inicial de exudación, $R_{\mathrm{B}}$ (se determina dentro de los primeros $30 \mathrm{~min}$. del ensayo) para los cementos con 20 y $30 \%$ de adición, es mayor en aquellos con puzolana. Lo contrario sucede con los cementos con 40 y $50 \%$ de adición figura 7 (a).

En la figura 7 (b) se observa que la capacidad de exudación, $C_{\mathrm{B}}$ (máxima cantidad de agua exudada, constante entre $10 \mathrm{~min}$.) de los morteros de cementos con cenizas volantes, es mayor que en aquellos de cemento con puzolana, salvo para el C-20. Pero, el mortero confeccionado con este cemento tiene una fluidez menor que el mortero con P-20, lo que explicaría esta excepción, ya que tendría menos agua para exudar.

El cemento P-50 presenta valores de $R_{\mathrm{B}}$ y $C_{\mathrm{B}}$ bajos, debido a que los cementos más gruesos exudan más (5) y como ya se mencionó, este cemento es el más fino. Por lo tanto, se podría esperar que P-50 aumente los valores de $R_{\mathrm{B}}$ y $C_{\mathrm{B}}$ si disminuyera su finura.

Las características especificas del cemento también pueden influir en la exudación. Por ejemplo, cuanto más tardío es el fraguado inicial y cuanto más largo es el periodo durante el cual el mortero permanece en estado plástico; tanto más se prolonga el proceso de sedimentación hasta que el endurecimiento inicial inmoviliza dicho proceso. Esto concuerda con lo obtenido en ambos tipos de cemento. $C_{\mathrm{B}}$ es mayor en los cementos con cenizas volantes debido a que tienen
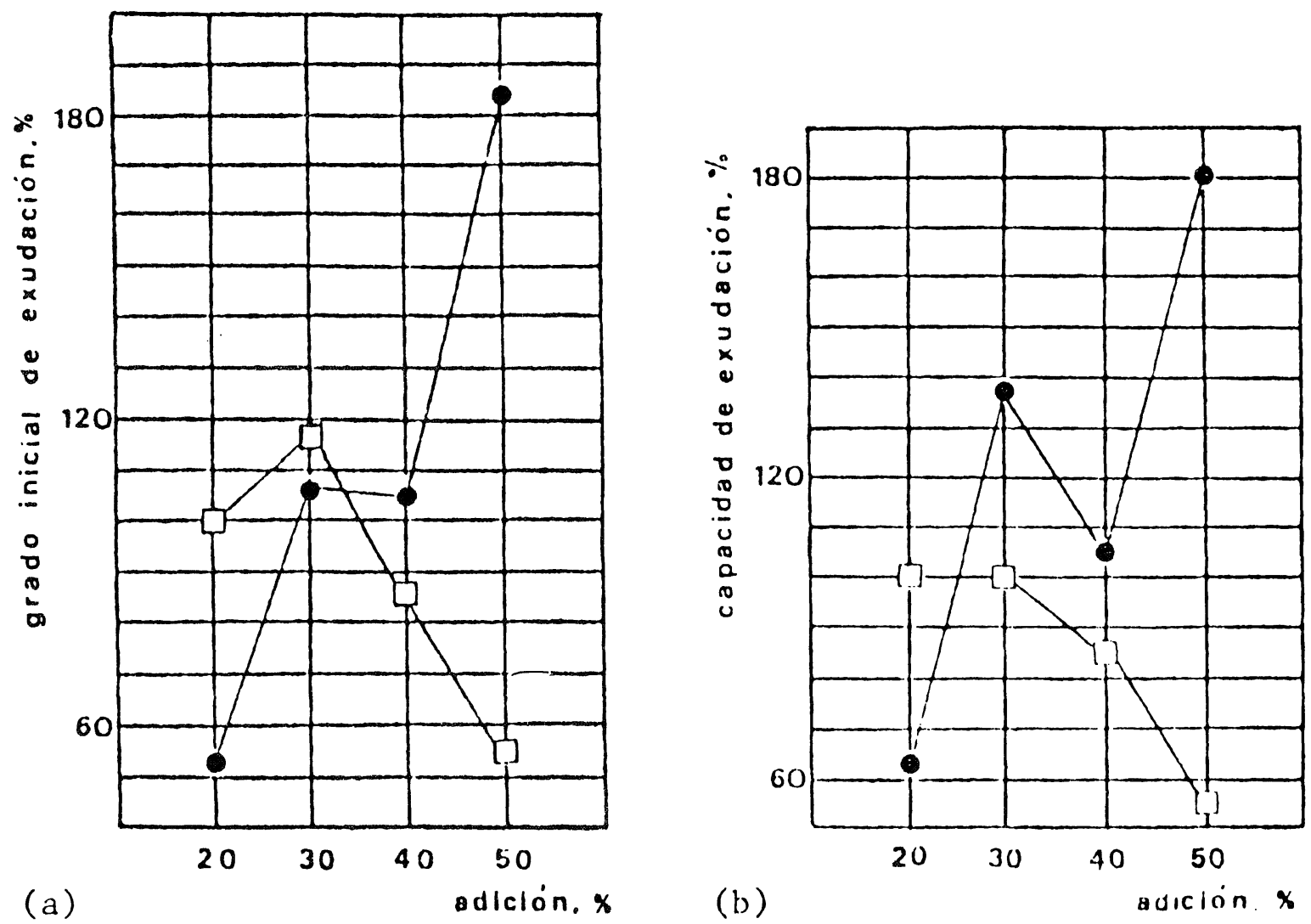

Fig. 7.-Resultados de ensayos de exudación. (a) Grado inicial de exudación. (b) Capacidad de exudación.

$\square$ : Cementos con puzolana natural.

- Cementos con cenizas volantes. 
mayores tiempos de fin de fraguado. $R_{\mathrm{B}}$ es mayor en los cementos con puzolana, porque ló cementos con cenizas volantes tienen mayor capacidad de retención de agua.

\section{Retentividad de los cementos}

Los cementos con cenizas volantes presentan una tendencia a retener más el agua, que aquellos con puzolana. Los valores más altos de retención de agua corresponden a los cementos con $20 \mathrm{y}$ $30 \%$ de adición. Ver figura 8.

La mayor retención de agua presentada por los cementos con cenizas volantes podría deberse a que éstos requieren una cantidad de agua menor para obtener una determinada fluidez, posiblemente a causa de la forma esférica de las cenizas, lo que permite reducir el porcentaje de huecos y un mejor acomodamiento del mortero. También podría influir en la retención de agua, la formación de la película semi-permeable alrededor de las partículas de cenizas.

\section{Contracción por secado}

La contracción por secado de los morteros de cementos con cenizas volantes disminuye, a medida que aumenta el porcentaje de adición. Lo contrario sucede con los morteros de cementos con puzolana (figura 9). Se verificó también que los cementos con cenizas sufren una menor contracción que aquellos con puzolana, lo que concuerda con lo mencionado por Venuat (6); Cabrera y Plowman (7), referente a que las cenizas reducen la contracción.

Los cementos más finos exhiben una mayor contracción, también según $\mathrm{M}$. Venuat, y en este trabajo se ha encontrado que el cemento P-50, que tiene una mayor finura, presenta también una mayor contracción que el resto de los cementos.

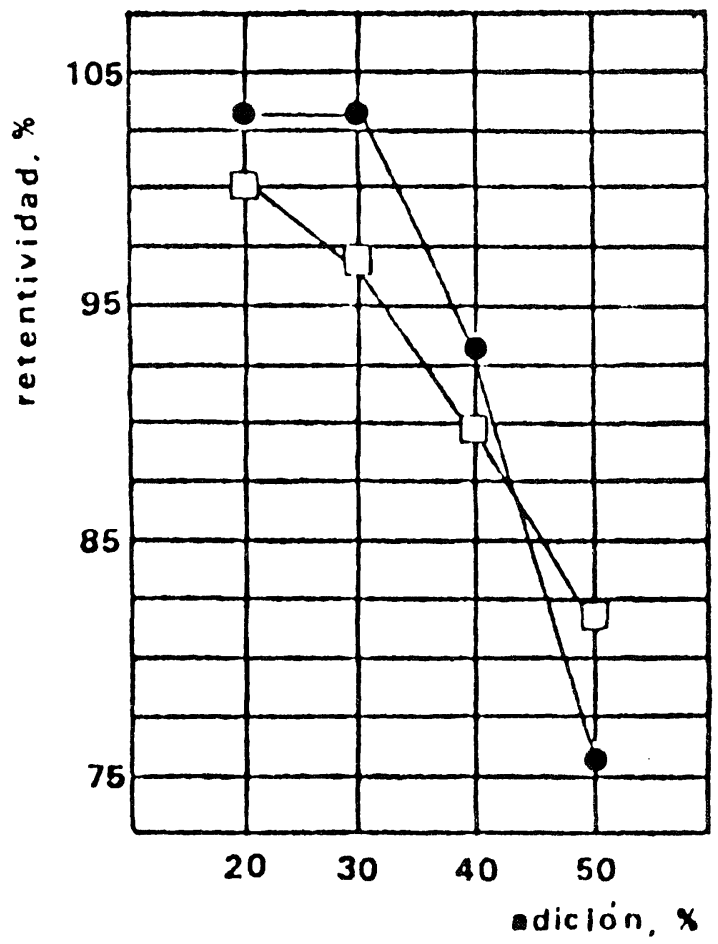

Fig. 8.-Retentividad de cementos experimentales.

$\square$ : Cementos con puzolana natural.

- Cementos con cenizas volantes.

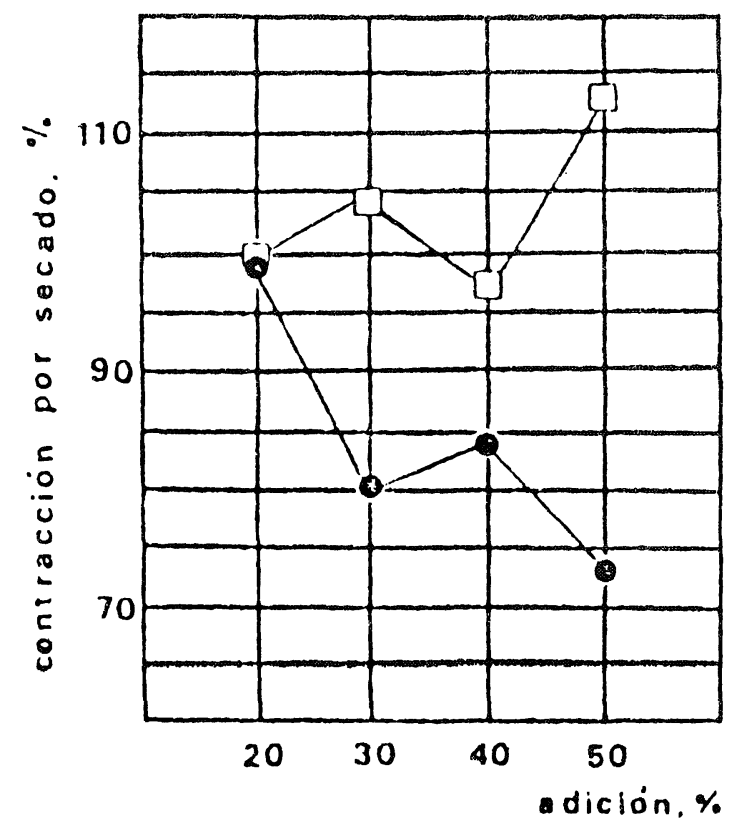

Fig. 9.-Resultados de ensayos de contracción por secado.

$\square$ : Cementos con puzolana natural.

- Cementos con cenizas volantes. 
El cemento P-50 necesitó una mayor cantidad de agua, para obtener una determinada fluidez y como la contracción por secado se produce al retirar el agua del mortero almacenado al aire sin saturar, se justificaría que este cemento presente una contracción por secado mayor.

M. Venuat comprobó que los cementos con adiciones de álcalis y cloruros presentan valores crecientes para la contracción (a la edad de 28 días). Se explicaría asi, en parte, la mayor contracción de los cementos con puzolana, ya que el contenido de álcalis en la puzolana es mayor que el contenido de álcalis en la ceniza volante.

\section{Resistencias mecánicas de los cementos}

Las resistencias de los cementos disminuyen, al aumentar el porcentaje de adición. Las resistencias (flexotracción y compresión) de los morteros de cementos con puzolana son mayores a tempranas edades (hasta los 13 días) y menores a posteriores edades, que las obtenidas con morteros de cementos con cenizas volantes. Se exceptúa los cementos con $50 \%$ de adición, debido a la menor finura de C-50 (figuras $10,11,12$ y 13).

Según Cabrera y Plowman (7) el aumento de resistencia a mayores edades que sufren los morteros de cementos con cenizas volantes, se debe a la influencia ejercida por la ceniza sobre el $\mathrm{C}_{3} \mathrm{~A}$ y $\mathrm{C}_{4} \mathrm{AF}$. Un retardo de la hidratación del $\mathrm{C}_{3} \mathrm{~A}$ y $\mathrm{C}_{4} \mathrm{AF}$, reduce el calor liberado y estimula la formación de silicatos hidratados.

La disminución sufrida en las resistencias mecánicas por los cementos a medida que aumenta el porcentaje de adición, es menos drástica en el caso de las resistencias a flexotracción que en las resistencias a compresión.

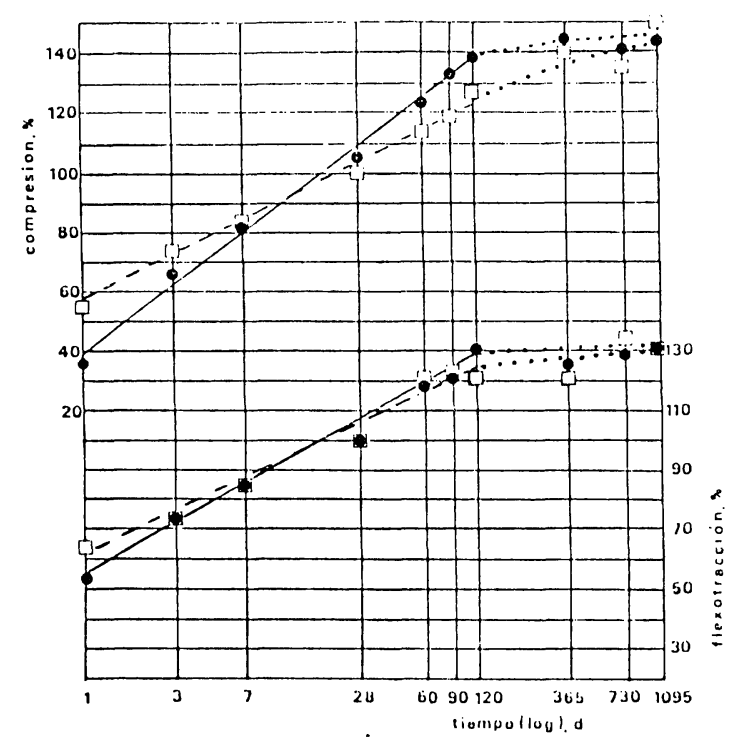

Fig. 10.-Resistencias mecánicas de morteros de cemento con $20 \%$ de adición.

- - $\square$ - -: Cemento cor puzolana natural.

$$
\begin{aligned}
& R_{\mathrm{f}}=31 \times \log \mathrm{t}+61 . \\
& R_{\mathrm{c}}=33 \times \log \mathrm{t}+56 .
\end{aligned}
$$

- - Cemento con cenizas volantes.

$$
\begin{aligned}
& R_{\mathrm{f}}=36 \times \log \mathrm{t}+54 . \\
& R_{\mathrm{c}}=48 \times \log \mathrm{t}+39 .
\end{aligned}
$$

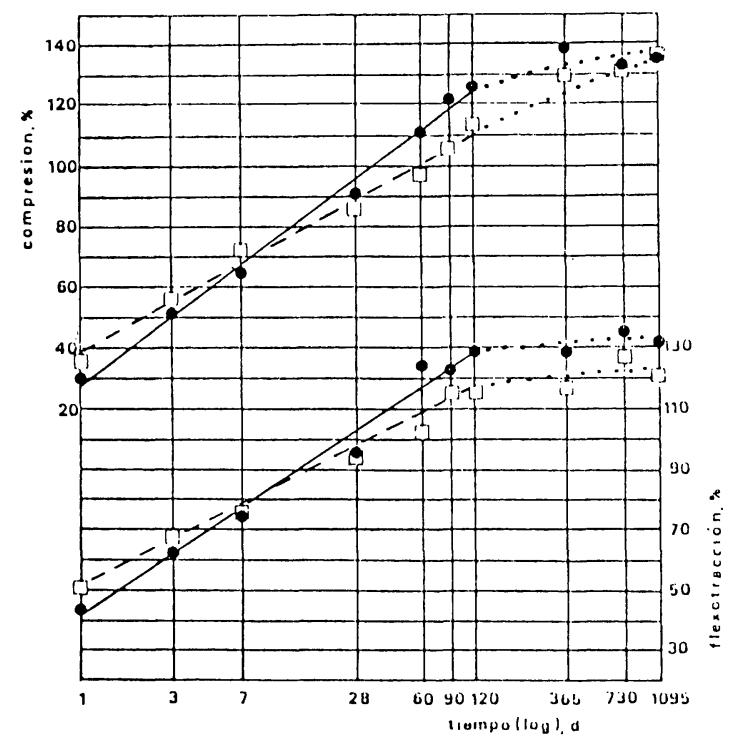

Fig. 11.-Resistencias mecánicas de morteros de cemento con $30 \%$ de adición.

$$
\begin{aligned}
-\square--: & \text { Cemento con puzolana natural. } \\
& R_{\mathrm{f}}=31 \times \log \mathrm{t}+51 . \\
& R_{\mathrm{c}}=35 \times \log \mathrm{t}+38 . \\
- & \text { Cemento con cenizas volantes. } \\
& R_{\mathrm{f}}=42 \times \log \mathrm{t}+41 . \\
& R_{\mathrm{c}}=46 \times \log \mathrm{t}+28 .
\end{aligned}
$$




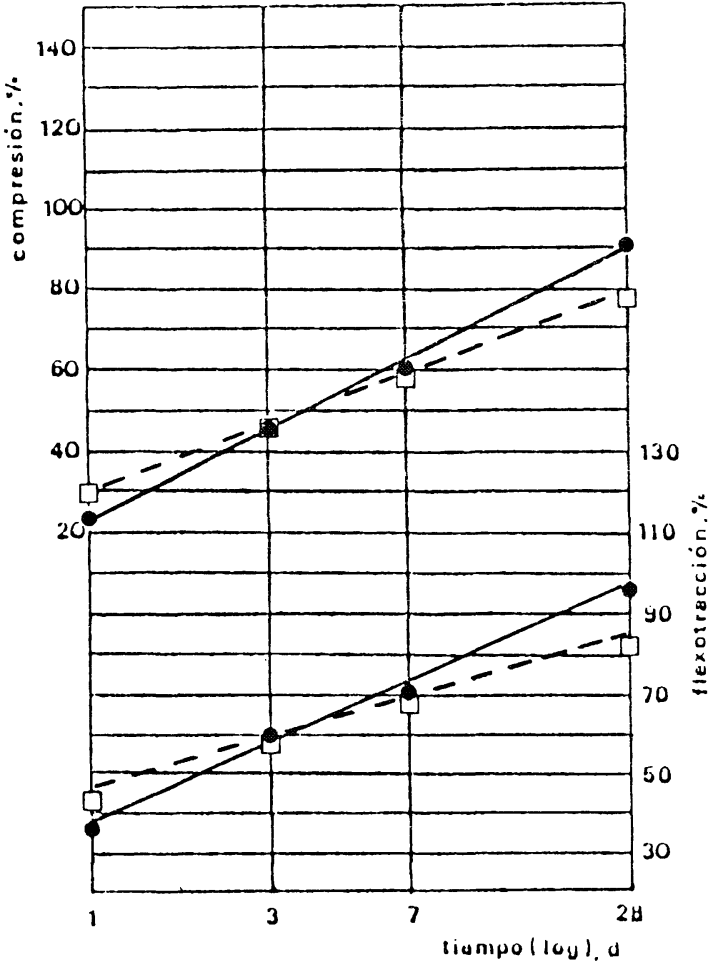

Fig. 12.- Resistencias mecánicas de morteros de cemento con $40 \%$ de adición.

- - $\square$ - -: Cementos con puzolana natural.

$R_{\mathrm{f}}=27 \times \log \mathrm{t}+44$.
$R_{\mathrm{c}}=34 \times \log \mathrm{t}+30$.

- - Cemento con cenizas volantes.

$R_{\mathrm{f}}=41 \times \log \mathrm{t}+38$.

$R_{\mathrm{c}}=46 \times \log \mathrm{t}+23$.

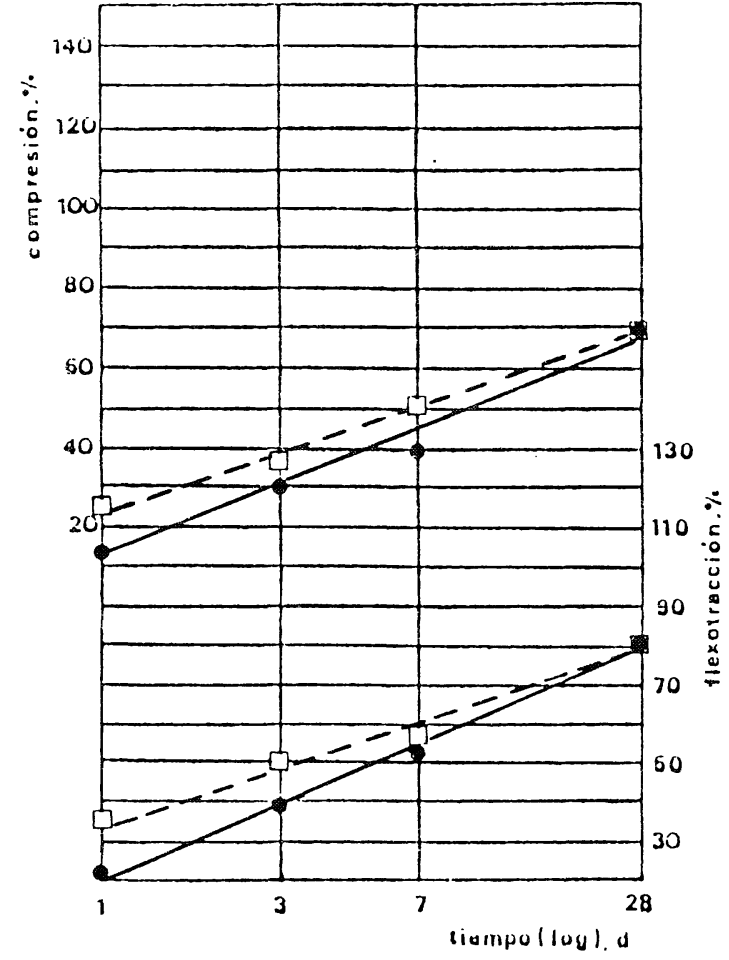

Fig. 13.--Resistencias mecánicas de morteros de cemento con $50 \%$ de adición.

- - $\square$ - - : Cemento con puzolana natural.

$$
\begin{aligned}
& R_{\mathrm{f}}=31 \times \log \mathrm{t}+35 . \\
& R_{\mathrm{c}}=31 \times \log \mathrm{t}+24 .
\end{aligned}
$$

- Cemento con cenizas volantes.

$R_{\mathrm{f}}=41 \times \log \mathrm{t}+20$.

$R_{\mathrm{c}}=38 \times \log \mathrm{t}+12$.

\section{CONCLUSIONES}

- Ambos tipos de cementos experimentales cumplen (casi en su totalidad) con los requisitos en las normas consultadas durante la realización de este trabajo (Normas INN y ASTM). Relacionando los cementos fabricados a nivel de laboratorio y a escala industrial, se tiene que la calidad de fabricación de los cementos experimentales resultó adecuada.

- Ambos tipos de cementos cumplen con los requisitos químicos especificados en la norma NCh 148. Of 68., para los cementos con agregado puzolánico. Los residuos insolubles y las pérdidas por calcinación de los cementos con cenizas volantes a igualdad de porcentaje de adición, resultaron menores que los de aquellos con puzolana.

- Tanto la puzolana como las cenizas volantes cumplen con los requisitos de la norma NCh 161. E Of 68., sobre actividad puzolánica. A la edad de 7 días la actividad puzolánica de las cenizas volantes es menor (18\% en promedio), que la actividad de la puzolana. Sin embargo, a edades posteriores, las actividades puzolánicas de ambas adiciones serán similares.

El agua necesaria para obtener la consistencia normal de la pasta puzolana-cal es menor, que la requerida por la pasta cenizas volantes-cal $(7 \%)$.

- La cantidad de agua para obtener la consistencia normal de los cementos con cenizas 
volantes es menor que la requerida por los cementos con puzolana. Esta menor cantidad de agua varía entre 4 y $13 \%$, según aumenta el porcentaje de adición.

- Los tiempos de inicio y fin de fraguado de los cementos con cenizas volantes son aproximadamente un $27 \%$ mayores (en promedio) que los que aquellos con puzolana. El intervalo de tiempo entre inicio y fin de fraguado es similar (en promedio) en ambos tipos de cementos. Este intervalo varía entre 2 y $6 \%$, según aumenta el porcentaje de adición.

- Las expansiones experimentadas por los cementos con cenizas volantes fueron menores entre un 9 y $66 \%$ que las de los cementos con puzolana. Las mayores diferencias se encuentran para los cementos con 30 y $40 \%$ de adición.

- Los cementos con 20 y $30 \%$ de ambos tipos de adición no cumplieron con lo especificado en la norma ASTM C 186-78, sobre calores de hidratación liberados a 7 y 28 dias. En cambio, aquellos con 40 y $50 \%$ de adición cumplen con esos requisitos. La norma INN NCh 148. Of 68. no señala exigencias en este aspecto.

Los calores de hidratación liberados por ambos tipos de cementos son similares. Estos son liberados casi en su totalidad en las primeras edades (hasta 7 días).

- Los morteros de cementos con cenizas volantes presentan una menor contracción por secado, que los de cementos con puzolana. En estos últimos, la contracción por secado, es mayor a medida que el porcentaje de adición aumenta. En cambio, en aquellos con cenizas volantes ocurre lo contrario.

- Los cementos con cenizas volantes presentan una capacidad de retención de agua mayor que aquellos con puzolana. El óptimo de retención parece estar en los cementos con $30 \%$ de adición.

- La exudación de ambos tipos de cementos depende más de la finura que del porcentaje de adición presente en los cementos. La norma INN NCh 148. Of 68. no establece ninguna exigencia en este aspecto.

- Los cementos con cenizas volantes presentan una tendencia a necesitar una cantidad de agua menor que aquellos con puzolana, para obtener una determinada fluidez.

- Las resistencias mecánicas de los morteros ensayados a tempranas edades son menores en los de cementos con cenizas volantes, que los de cementos con puzolana. Este comportamiento se mantienen hasta la edad de 13 días aproximadamente. Las resistencias mecánicas de los morteros ensayados a posteriores edades son mayores en los de cementos con cenizas volantes que en los de cementos con puzolana.

\section{B I B L I O G R A F I A}

(1) A. JARRIGE (1971): "Las cenizas volantes: propiedades, aplicaciones industriales". Eyrolles, París.

(2) R. MILLER y R. COLLINS (1976): "Materiales de desecho como potencial reemplazo para agregados ligeros". NCHRP Report N. ${ }^{\circ} 166$, Transportation Research Board, Washington D.C.

(3) REVISTA COMBUSTION, octubre 1974: "Nuevo enfoque para la ceniza volante".

(4) F. KEIL (1973): “Cemento: fabricación, propiedades y aplicaciones”. Editores Técnicos Asociados, S. A., Barcelona.

(5) A. M. NEVILLE (1977): "Tecnologia del concreto". IMCC, Méjico.

(6) M. VENUAT y M. PAPADAKIS (1968): "Fabricación, características y aplicaciones de los diversos tipos de cementos". Editores Técniccs Asociados, S. A., Barcelona.

(7) J. G. CABRERA y C. PLOWMAN (1980): "The influence of pulverized fuel ash on the early and long term strength of concrete". 7. ${ }^{\circ}$ Congres International de la Chimie des Ciments. Vol. II, IV-84, Paris.

(8) DelmaR L. BLOEM (1954): "Effect of fly ash in concrete". Publication N. ${ }^{\circ} 48$. 